\title{
Saddle Node Bifurcation Point Analysis of Voltage Stability of IEEE 30-BUS Power System for Removal of Generation through Bacteria Foraging Optimization Algorithm
}

\author{
Srikanth B. Venkata ${ }^{1 *}$, Lakshmi Devi Aithepalli ${ }^{2}$ \\ ${ }^{1}$ EECF, VALF, SDSC Satish Dhawan Space Centre, Indian Space Research Organization, Sriharikota, Andhra Pradesh, India-524124. \\ ${ }^{2}$ Department of Electrical and Electronics Engineering, Sri Venkateswara University, Tirupati, Andhra Pradesh, India-517205. \\ *Corresponding author E-mail: srikanthbv.shar@gmail.com
}

\begin{abstract}
This paper deals with the identification of instability nodes of IEEE 30 BUS power system to generation removal. Optimal sizing and locations of reactive power compensations are obtained. Firstly one of the generators is assumed to be removed from service and the saddle node bifurcation (SNB) point voltages are evaluated without reactive power compensation. Secondly two generators are assumed to be removed from service and the saddle node point voltage magnitudes are obtained without reactive power compensation. For both cases the study is conducted by placing optimal reactive power compensations at optimal locations using Bacterial Foraging Optimization Algorithm (BFOA).
\end{abstract}

Keywords: Voltage stability, SNB point voltage magnitude, Static Var compensation (SVC), BFOA

\section{Introduction}

The modern power systems are still expanding because of phenomenal growth in load demand. The present day power systems are becoming more complex because of the participation of public and private utilities. Hence the operation and control of the system is becoming more complex.

The need of the hour is to maintain the security of power system with abnormal circumstances to avoid voltage instability and blackouts. Sufficient studies are required at the planning stage itself to improve the operation and control of power system. Lot of research work is reported in literature to improve the steady voltage in power systems.

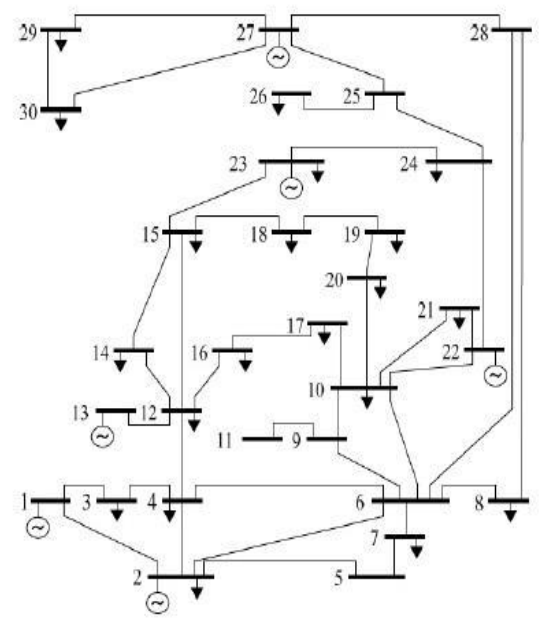

The main objective of the work reported in this paper is to study the effect of removal of generation(s) on steady voltage of IEEE 30 BUS power system and it's improvement with Static optimal reactive power compensation at optimal locations. The standard IEEE 30 BUS power system is presented in Fig.1.

\subsection{Formulation of Voltage Stability Problem and Methodology}

Voltage stability problem and the solution method attempted in this work is briefly explained. Initially Alternate Current (AC) load flow study has been carried out using Continuation Power flow method to get steady state voltage profile under base case. Initial list of contingencies for further study are prepared. Then multiple load flows are carried out, by incorporating one contingency at a time and this information stable or unstable condition on PV Curve are calculated. From this information critical voltage saddle node points are calculated. Based on Voltage performance can be penalized when voltage drop is more than maximum allowed voltage deviation from the nominal voltage. Based on voltage values, a list of severe contingencies is prepared.

Contingency level for each bus is calculated for each contingency. The bus which has low per unit (p.u) is most suitable for locating reactive support device such as Static Var Compensator (SVC). To confirm the location of the devices, a BFOA method is used for finding required reactive power capacity needed for voltage stability condition. After placing reactive support device at the identified optimal location, again AC load flow study has been carried out for both base and contingency case. The above procedure has explained through block diagram which is shown in Fig. 2.

Fig. 1: IEEE 30 BUS power system single line diagram. 


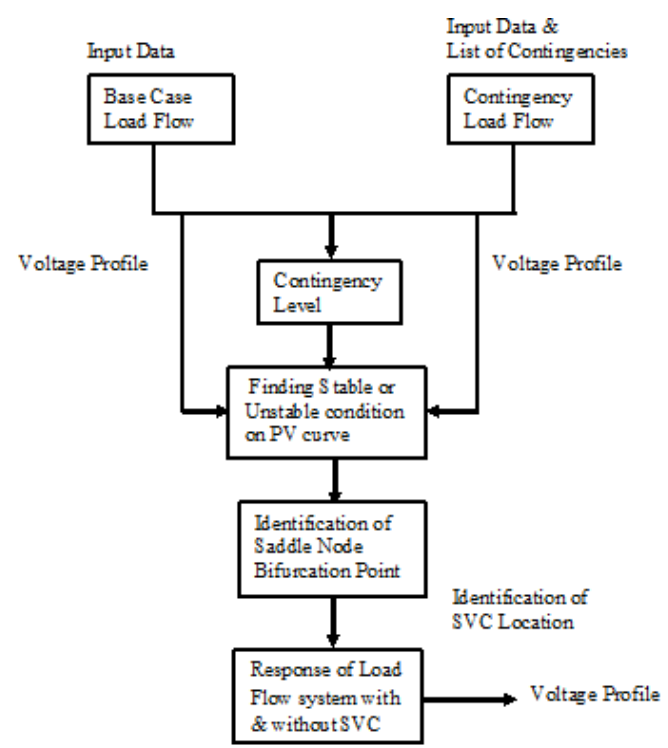

Fig. 2: Out line of work done

\subsection{Problem Definition}

The proposed work objective function is to acquire the optimal location as well as size of SVC and optimal location; this reduces an active power loss as well as total voltage deviation.

$F=\left[f_{1}, f_{2}\right]$

Whereas $f_{l}$ represents the real power loss and $f_{2}$ denotes the total voltage deviation (VD) for all the load buses from preferred value of 1.0 per unit (p.u), respectively.

$$
\begin{aligned}
& f_{1}=P_{\text {Loss }}=\sum_{i=1}^{N L} \quad g_{i j}\left(V_{i}^{2}+V j^{2}-2 V_{i} V j \cos (\delta i-\delta j)\right) \\
& f_{2}=\mathrm{VD}=\sum_{i=1}^{n P Q} \quad\left(\mathrm{~V}_{\mathrm{i}}-\mathrm{V}_{\mathrm{i}}{ }^{\text {ref }}\right)^{2}
\end{aligned}
$$

where

$\mathrm{V}_{\mathrm{i}}$ - Magnitude of voltage at bus $\mathrm{i}$

$\mathrm{V}_{\mathrm{j}}$ - complex voltage at load bus $\mathrm{j}$

$\mathrm{g}_{\mathrm{i}, \mathrm{j}}$ - conductance of line $\mathrm{i}-\mathrm{j}$

$\boldsymbol{\delta} \mathrm{i}$ - voltage angle at bus $\mathrm{i}$

$\mathrm{N}_{\mathrm{L}}$ - total number of transmission lines

VD - voltage deviation

nPQ - number of PQ buses

$\mathrm{V}_{\mathrm{i}}$ - voltage magnitude at load bus $\mathrm{i}$

$\mathrm{V}_{i}^{\text {ref }}$ - pre-specified reference value of the voltage magnitude at the $\mathrm{i}^{\text {th }}$ load bus.

The problem of minimization is subject to the following equality and inequality constraints like

\section{Load flow constraint}

$P_{G i}^{\text {min }} \leq P_{G i} \leq P_{G i}^{\max }$, for $i=1,2, \ldots . . n P V$

$Q_{G i}^{{ }^{\min } \leq Q_{G i} \leq Q_{G i}{ }^{\max } \text {, for } i=1,2, \ldots . . n P V}$

Whereas, $P_{G i}{ }^{\text {min }}$, and $Q_{G i}{ }^{\text {min }}$ are minimum limits of bus $i$ real power generation as well as bus i reactive power generation, respectively. $P_{G i}{ }^{\max }$, and $Q_{G i}{ }^{\max }$ are maximum limits of bus i real power generation as well as bus i reactive power generation, respectively.

\section{Voltage constraint}

$V_{i}^{\min } \leq V_{i} \leq V_{i}^{\max }$, for $i=1,2, \ldots . . n P V$
Where

$V_{i}^{m i n}$ is minimum limits of bus $i$ Voltage magnitude.

$V_{i}^{\text {max }}$ is maximum limits of bus $i$ Voltage magnitude.

\section{Reactive Power of SVC}

$Q_{S V C}{ }^{\min } \leq Q_{S V C} \leq Q_{S V C}{ }^{\max }$

Where

$Q_{S V C}{ }^{m i n}$ is minimum limits of Reactive Power of SVC

$Q_{S V C}{ }^{\text {max }}$ is maximum limits of Reactive Power of SVC

Transmission line flow limit

$S_{L i} \leq S_{L i}^{\max }, i=1,2 \ldots . . N L$

Where

$S_{L i}$ Power flow of the line i

\subsection{Bacteria Foraging Optimization Algorithm}

Generally, Bacteria Foraging concept is derived from the usual behavior of animal hunting for nutrient to boost-up its energy for foraging. The proposed algorithm is also based on the same principle which shows the $E$. coli searching behavior. E. coli microorganism has searching quality of food is faster than others. The chemotaxis is a usual foraging characteristic of bacteria, this assists to grab necessary nutrient. For execution of steps in chemotaxis, the below searching procedure is followed. Let " $\mathrm{j}$ " is chemotaxis stepping rate, $\mathrm{k}$ is the production step as well as "l" is the elimination dispersal event index.

Bacteria life time length $(\mathrm{Nc})$ is calculated by the number of steps involved in chemotoxix. Bacteria freely swim in the space to condense the loss; together with highest number of steps (Ns). Reproduction is assumed after chemotaxis processs. For population sorting, the number of reproduction steps involved by bacteria is (Nre). Bacteria reproduction is carried out to amplify the population. A lot of nutrients will be provided to the bacteria by this technique and it keeps the steady population scale.

For initialization, we have to select $S, p, N s, N_{e d}, p_{e d}, N_{r e}, N_{c}$, as well as C(i), i equals $1,2, \mathrm{~K}, \mathrm{~S}$. To use swarming, it's necessary to select the parameters which are based on cell-to-cell attractant functions; the parameters specified over are used here. In addition, the $\theta_{\mathrm{i}}$ primary values; $\mathrm{i}=1,2, \mathrm{~K}, \mathrm{~S}$ should selected. Selecting the same areas of these parameters where a best value and it is suitable to exist in superior option. Instead, the simple arbitrarily distribution across the area is needed for the issue of optimization. An algorithm which forms chemotaxis of bacterial population, reproduction, swarming, dispersal and elimination is specified here (initially, $\mathrm{j}=\mathrm{k}=\mathrm{l}=0$ ). From the algorithm note that, the updates to the $\theta_{\mathrm{i}}$ which automatically updates the P. Obviously, it could have added more sophisticated execution test than simply identifying a highest number of iterations.

Step1: Removal dispersal loop: $\mathrm{i}=\mathrm{i}+1$;step 2: Reproduction loop: $\mathrm{k}=\mathrm{k}+1$; Step 3: Chemotaxis loop: $\mathrm{j}=\mathrm{j}+1$, For $\mathrm{i}=1,2, \mathrm{~K}, \mathrm{~S}$ take a chemotactic step for bacterium $i$ as follows. Calculate $J(i, j$, $\mathrm{k}, \mathrm{l})$. Let $\mathrm{J}(\mathrm{i}, \mathrm{j}, \mathrm{k}, \mathrm{l})=\mathrm{J}(\mathrm{i}, \mathrm{j}, \mathrm{k}, \mathrm{l})+\mathrm{J}_{\mathrm{cc}}\left(\theta_{\mathrm{i}}(\mathrm{j}, \mathrm{k}, \mathrm{l}), \mathrm{p}(\mathrm{j}, \mathrm{k}, \mathrm{l})\right.$ ) (i.e., add on the cell to cell attractant result to the nutrient attention.)

Let $\mathbf{J}_{\text {last }}=\mathrm{j}(\mathrm{i}, \mathrm{j}, \mathrm{k}, \mathrm{l})$ to keep this value while one can get a good rate via a run.

Tumble: Produce a arbitrary vector $\Delta(\mathrm{i}) \in \mathrm{p}$ with all elements $\mathrm{m}(\mathrm{i}), \mathrm{m}=1,2, \mathrm{k}, \mathrm{p}$ a arbitrary number on $[-1,1]$.

Move: Let

$\theta^{\mathrm{i}}(\mathrm{j}+1, \mathrm{k}, \mathrm{l})=\theta^{\mathrm{i}}(\mathrm{j}, \mathrm{k}, \mathrm{l})+\mathrm{C}(\mathrm{i}) \frac{\Delta(\mathrm{i})}{\sqrt{\Delta^{\mathrm{T}}(\mathrm{i}) \Delta(i)}}$ 
This consequences in a step of size C(i) in the way of the topple for bacterium i.

Calculate $J(i, j+1, k, l)$, consider $J(i, j+1, k, 1)=J(i, j+1, k, 1)+J c c$ $\left(\theta_{i}(j+1, k, 1), P(j+1, k, 1)\right)$. Swim (note that an estimation is used as it have been decided as that swimming nature of every cell as if the bacteria numbered $\{1,2, K, i\}$ have stimulated and $\{i+1, i+2, K$, S \} have not; this is a lot easier to simulate and then immediate decisions made on swimming and tumbling by all bacteria at a equal time.

Let $\mathrm{m}=0$ (counter for swim length).

While $\mathrm{m}<\mathrm{Ns}$ (if not climbed down very long)

Let $m=m+1$.

If $\mathrm{J}(\mathrm{i}, \mathrm{j}+1, \mathrm{k}, \mathrm{l})<\mathrm{J}$ last (if doing good), let $\mathrm{J}$ last $=\mathrm{J}(\mathrm{i}, \mathrm{j}+1, \mathrm{k}, \mathrm{l})$ and let

$$
\theta^{\mathrm{i}}(\mathrm{j}+1, \mathrm{k}, \mathrm{l})=\theta^{\mathrm{i}}(\mathrm{j}+1, \mathrm{k}, \mathrm{l})+\mathrm{C}(\mathrm{i}) \frac{\Delta(\mathrm{i})}{\sqrt{\Delta^{\mathrm{T}}(\mathrm{i}) \Delta(i)}}
$$

Else, let $\mathrm{m}=$ Ns. It will end the 'while' statement. Go to subsequent bacterium $(i+1)$ if $i \neq S$ (i.e., go to $b$ ) to progression the subsequent Bacterium).

If $\mathrm{j}<\mathrm{Nc}$, go to step-3. In this situation, carry on chemotaxis, because the life of the bacteria is not completed.

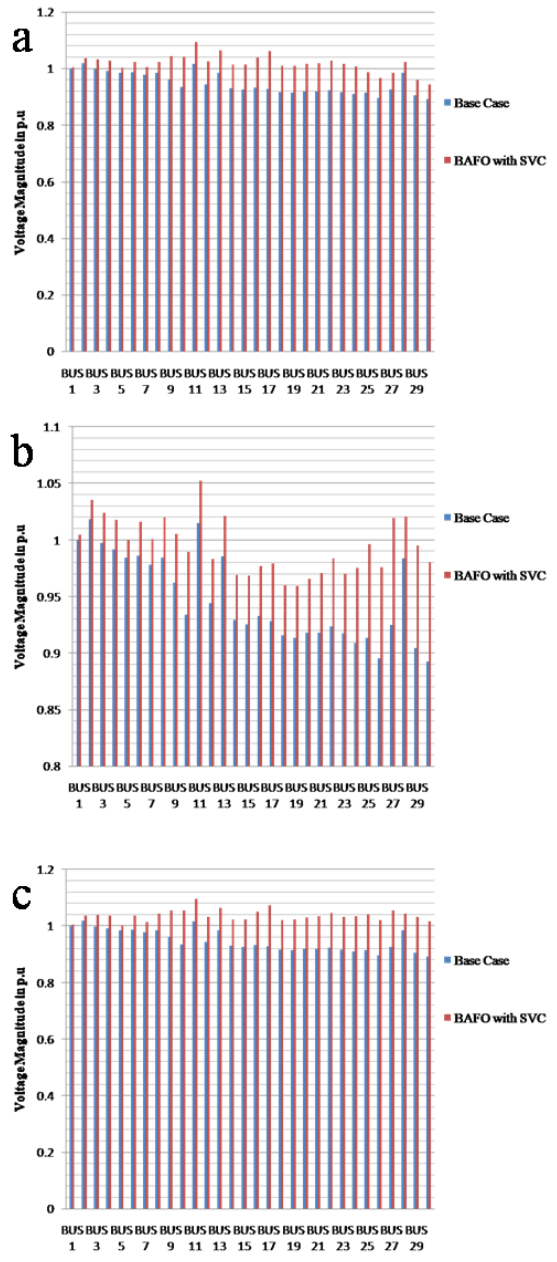

Fig. 3 :(a) SNB point of each bus Voltage magnitudes for IEEE 30 BUS System with and without SVC (a) case1-SVC at bus17, (b)case2- SVC at bus 27 and (c) case3-SVC at buses $17 \& 27$

\subsection{Reproduction}

a) For known $\mathrm{k}$ as well as 1 , and for $\mathrm{i}=1,2, \mathrm{~K}, \mathrm{~S}$, let the bacterium $i$ health (compute how many nutrients it completed in its duration; how successful it is at evading toxic materials).
Arrange bacteria and chemotaxis factors (i) in order to ascending the cost $\mathrm{J}$ health (superior cost means poorer health).

$$
\mathrm{J}^{\mathrm{i}}{ }_{\text {health }}=\sum_{j=1}^{N e+1} J(i, j, k, l)
$$

b) The $S_{r}$ bacteria had maximum $J$ health rates will expire and other $S_{\mathrm{r}}$ bacteria had the greatest values tear (and copies finished, located at identical place as their parent).

Step 4: If $\mathrm{k}<\mathrm{N}_{\mathrm{re}}$, consider step-2. In this situation, we were not attained an amount of particular reproduction steps, thus it can be started the subsequent age group in chemotaxis loop.

Step 5: Removal dispersal: For I equal 1, 2, K, S, with probability $\mathrm{p}_{\text {ed }}$, remove as well as dissolve each bacterium (it maintains the constant population of the bacteria). To make this, if you remove a bacterium, it can simply dissolve one to an arbitrary place on an optimization area.

Step 6: If $1<\mathrm{N}_{\mathrm{ed}}$, then consider step-1; or else end.

\section{Numeric Simulation}

The IEEE 30 Bus power system line diagram is considered for this study. The power flow analysis and the determination of saddle node point voltage magnitudes for various configurations of the system under consideration are evaluated with the help of continuation power flow method. The optimal sizing and optimal locations are obtained with the help of BFOA and voltage magnitudes of SNB points of the system using BFOA algorithms. The voltage assessment points are evaluated with BFOA with reactive power compensation. The analysis is carried out using MATLAB software. This procedure is repeated for normal and other types of contingencies.

\section{Results and Discussion}

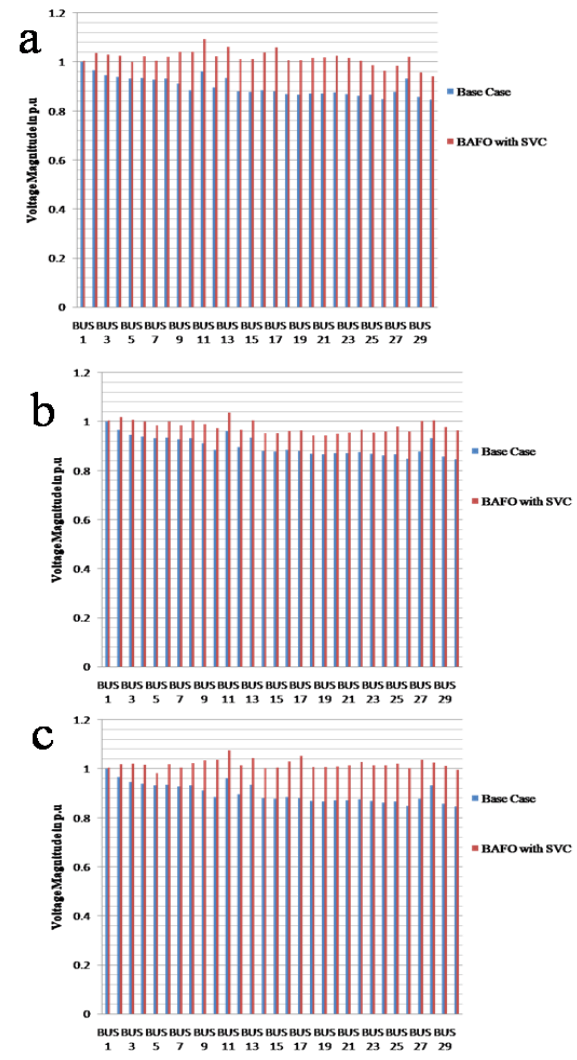

Fig. 4: (a) SNB point of each bus Voltage magnitudes for the present BUS System with and without SVC (a) case 4-SVC at 17, (b) case 5-SVC at 27 , and (c) case $6-\mathrm{SVC}$ at $17 \& 27$. 
The generator connected at bus 13 is assumed to be removed. The saddle point voltage magnitudes of all the buses are evaluated without rectify power compensation.

The optimal locations and optimal sizing of Static reactive power compensation are obtained through BFOA. The optimal locations are at $17^{\text {th }}$ Bus and $27^{\text {th }}$ bus. The corresponding optimal values are 56.21 MVAR and 29.84 MVAR respectively. The study is conducted with reactive power source only at bus 17 , at bus 27 and at both buses. The results are shown in Fig. 3.

The saddle point voltage magnitudes are low at buses 30, 26 and 29 the observation is that these voltage magnitudes are moderately improved with reactive power compensation is only at 17 and only at bus 27.These values are very much improved with compensation at both the optimal buses compared to those obtained without reactive power compensation.

The generations at bus 13 and bus 27 are assumed to be removed. The saddle point voltage magnitudes of all buses are evaluated without compensation. These voltage magnitudes are also obtained with optimal compensation placed at 17 Bus only, at 27 bus only and at both buses. The results are depicted in Fig. 4. It is observed the saddle point voltage magnitudes are low at buses 30 , 26 and 29.

With reactive power compensation only at bus 17 , only at 27 the voltage magnitudes are moderately improved. However the improvement is significant when reactive power compensation is at both the buses.

\section{Conclusion}

The saddle node bifurcation point voltage stability analysis is carried out on an IEEE 30-BUS power system for loss of generation (s). The optimal values and optimal locations of reactive power compensation are obtained using BFOA optimization technique. It is observed that the saddle node bifurcation point voltage magnitudes are moderately improved with reactive power compensation is only at bus 17 and at bus 27 . There is a significant improvement with compensation at both buses for the two cases under consideration.

\section{Acknowledgement}

Authors are thankful to the Prof B. Subramanyam for his valuable suggestions to this work. And also author thankful to my wife for her continuous support.

\section{References}

[1] E. Larsen, D. Baker, A. Imece, L. Gerin-Lajoie, G. Scott, "Basic aspects of applying SVC's to series-compensated AC transmission lines", Power Delivery, IEEE Transactions, 5, 3, (1990), 1466 1473 .

[2] A Text Book by P Kundur, "Power System Stability and Control", Tata McGraw Hill Company Private Limited, 2008.

[3] Y. Liu Y., Passino K.M., "Biomimicry of Social Foraging Bacteria for Distributed Optimization: Models, Principles, and Emergent Behaviors", Journal of Optimization Theory and Applications, 115, 3, (2002), 603-628.

[4] Taciana Menezes, Lulz da Silva, C.P., Carolina Affonso, Vivaldo da Costa, F., Secundino Soares, "MVAR Management on the Predispatch Problem for Improving Voltage Stability Margin”, IEEE Proceedings Generation, Transmission and Distribution, Volume no. 151 , no. 6, pp: 665-672, February 2002.

[5] Carolina Affonso, M., Luiz da Silva, C.P., Flavio Lima, G. M., Secundino Soares, "MW and MVAR Management on Supply and Demand Side for Meeting Voltage Stability Margin Criteria", IEEE Transactions on Power Systems, Vol. 19, no. 3, pp: 1538-1545, August 2004.

[6] Feng Dong, Badrul Chowdhury, H., Mariesa Crow, L., Levent Acar, "Improving Voltage Stability by Reactive Power Reserve Manage- ment", IEEE Transactions on Power Systems, Vol. 20, no.A1, pp: 338-345, February 2005.

[7] Arthit Sode-Yome, Mithulananthan, N., "Static Voltage Stability Study Using MATLAB Symbolic and Optimization Toolboxes", Royal Thai Government and Siam University, Thailand, January 2006.

[8] Claudia Reis, Maciel Barbosa, F.P., "A Comparison of Voltage Stability Indices",Electrotechnical Conference, Melecon, Benalmadena (Malaga), Spain, pp: 1007-1010, May 16-19, 2006.

[9] Tripathy M., Mishra, S., "Bacteria foraging-Based to Optimize Both Real Power Loss and Voltage Stability", IEEE Transactions on Power Systems, 22, 1, (2007).

[10] B.V. Srikanth, A. Lakshmi Devi, "Voltage Stability Analysis and Bifurcation Techniques: A detailed Survey", International Journal of Latest trends in Engineering and Technology, 6, 3, (2016), 9-16.

[11] B.V. Srikanth, A. Lakshmi Devi, "Voltage Stability Analysis IEEE 30 Bus System Using ContinuationPower Flow Method", International Conference on Emerging Trends in Electrical and Power Engineering, ICEEPE-2016, 4 th april 2016, volume -I, ISBN: 97893-5254-978-0, page 163-168.

[12] B.V. Srikanth, A. Lakshmi Devi, "Voltage Stability Analysis for IEEE 14 Bus System Using Static Var Compensator", International Journal of Electrical and Electronics Engineering Research, (2016), 247-254.

[13] B.V. Srikanth, A. Lakshmi Devi, "Optimal Location and sizing of SVC using genetic algorithm to find voltage saddle node points for improving voltage stability", International Journal of Pure and Applied Mathematics, 114, (2017), 474-489. 